\title{
Hydro-geological Analysis of an Industrial Plant in East Africa
}

\author{
Minfeng $\mathrm{LI}^{1 \text {, a }}$, Shengxin Shao ${ }^{1, \mathrm{~b}}$, Zhenyun Zhou ${ }^{1, \mathrm{c}}$, Bin Zhu ${ }^{1}$, \\ Yong Tao ${ }^{1}$, Yao Zhu ${ }^{1}$, Hao Jiang ${ }^{1}$ \\ 1. Shangtan Power Generation Co., Ltd, Shanghai, 200010, China \\ aliminfeng001@163.com; ${ }^{b}$ shaoshx@gmail.com; ${ }^{\text {zzzyun 9999@163.com }}$
}

Keywords: hydro-geological analysis; ground water; Magneto-Telluric Sounding (MTS) method; inversion; hydro-geological borehole; electrical logging method

Abstract: The geophysical prospecting, hydro-geological survey and a geological drilled borehole with the depth of 200 meters are used to ascertain the aquifer structure, hydro-geological conditions and preliminary hydro-geological parameters in an industrial plant project of East Africa. The magneto-telluric sounding method in combined with the borehole electrical logging method is adopted to analyze the ground water and hydro-geological parameters. The results show that the water abundance is very poor, and the estimated water flow in this area, even under the depth of 200 meters, is not enough to satisfy the production demand of this industrial plant.

\section{Introduction}

In most part of east Africa, water source like groundwater is very important for those countries. Some research like the groundwater exploitation and hydraulic parameter estimation for a Quaternary aquifer in Dar-es-Salaam was studied [1]. And the geology is the fundamental to find the groundwater, the geology research within Dar-es-Salaam City area shows that Quaternary deposits of Pleistocene to Recent periods have total thickness of approximately $150 \mathrm{~m} \mathrm{[2].} \mathrm{The}$ electromagnetic geophysical methods like magneto-telluric and magneto-telluric sounding methods are used to acquire formation resistivity information [3]-[5], and some electromagnetic geophysical methods are using to find out the ground water [6]-[9].

The study focuses on the hydrogeological investigation and characteristics of the area to find out the groundwater if it is satisfied the demand of the industrial plant in East Africa. The MagnetoTelluric Sounding (MTS) method is adopted to analyze the hydrogeological conditions in the plant area. In combined with the drilled borehole, the apparent resistivity and spontaneous potential log are inversed to estimate the groundwater flow in this area.

\section{General Geology Conditions in the Plant Area}

Strata and Tectonic Conditions. The surface loose layer in the plant area is sand bed, sandy clay exists only in gullies, and the soil conditions is comprsing: silty clay mixed with silt is dominant early Quaternary strata, within the depth of 50m; sand bed is dominant in late Neogene strata, mixed with clay layer, sand bed has very high shale component, although the thickness is high, the water abundance and transmissibility is very poor. And the bedrock mainly includes tertiary sand shale and Cretaceous glutenite, Mt. PUGU outcrops in the west of the plant area, is embedded very deeply in the rest areas.

Hydrogeological Conditions. The ground water in the plant area is mainly pore water in loose layer and bedrock weathering fissure water, pore water in loose layer mainly occurs in Quaternary strata and tertiary loose layer. Bedrock weathering fissure water mainly occurs in weathered strata at the juncture of bedrock and loose layer and in tectonic fissure, its water abundance might be better than loose layer, however, bedrock is buried very deeply in the plant area, plus dominant sand shale in neogene system, its weathering fissures would be filled by shale component, water abundance and transmissibility would also become poor, availability is reduced significantly. Makeup ground water 
in this area is mainly atmospheric precipitation recharge via vertical infiltration, lateral runoff recharge is dominant in bedrock aquifer, and the leakage recharge is auxiliary.

\section{MTS and Electrical Logging Method}

MTS Method. As the traditional MT method, the electromagnetic sounding method is used as the source of the natural electromagnetic field in the universe, such as the solar wind and lightning, which is a planar electromagnetic wave. The MTS method assumed the earth is a horizontal medium, and the electromagnetic field is a plane electromagnetic wave which is perpendicular to the ground. Its calculation formula is:

$$
\rho_{x y}=\frac{1}{5 f}\left|Z_{x y}\right|^{2}=\frac{1}{5 f}\left|\frac{E_{x}}{H_{y}}\right|^{2} \quad \rho_{y x}=\frac{1}{5 f}\left|Z_{y x}\right|^{2}=\frac{1}{5 f}\left|\frac{E_{y}}{H_{x}}\right|^{2}
$$

Where $f$ is the frequency $(\mathrm{Hz}) ; \rho$ is the resistivity $(\Omega . \mathrm{m})$, as the underground media is inhomogeneous, it's the apparent resistivity value;

The frequency dependent impedance $\mathrm{Z}$ is,

$Z=\left|\frac{E}{H}\right| e^{i\left(\varphi_{E}-\varphi_{H}\right)}$

Where $\varphi_{E}$ is the electric field phase, $\varphi_{H}$ is the magnetic field phase.

The MT skin depth (depth of penetration, investigation depth) from the measured can be estimated by [4],

$$
\delta=503 \sqrt{\frac{\rho}{f}}
$$

$\delta$ is the skin depth, it follows the change of resistivity and frequency.

Electrical logging method. A set of electrode system is placed in the 200 meters drilled well, when the electrode system moves along the shaft, the electric current supplied by powered electrode A and B flowed through the strata, the potential difference (PD) is measured by the other two electrode $\mathrm{M}$ and N. In terms of the PD and supply current, the electric resistivity could be ascertained. And the homogeneous media electric resistivity is,

$$
\rho_{s}=\frac{4 \pi \cdot A M \cdot A N}{M N} \cdot \frac{\Delta V_{M N}}{I}=\frac{K \cdot \Delta V_{M N}}{I}
$$

$K$ is the coefficient of electrode array device, as the distance between the four electrodes is fixed, so $K$ is a constant, as this project, the constant $K=57.55 \mathrm{~m}$.

Measuring-line arrangement. In terms of the characteristics and the geological conditions of the plant area, the east-west and south-north geophysical prospecting line is arranged through the plant area (see fig.1). There are 5 measuring line, the total length is $4675 \mathrm{~m}$ with measuring 195 points.

\section{Test Results}

After MTS field data in time series is preprocessed, FFT transform is performed to get imaginaryreal component and phase data of electric field and magnetic field. The one-dimensional, twodimensional inversion imaging with terrain and topographic correction is carried out. 


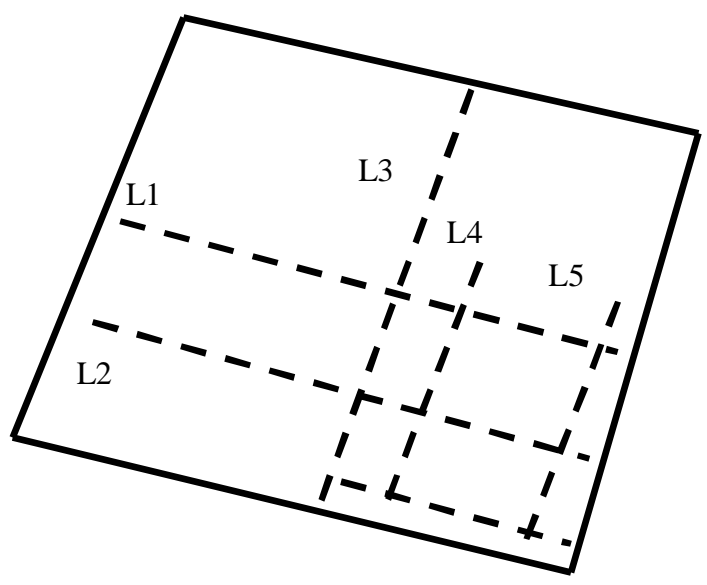

Fig.1. Arrangement of the measuring-line

Data inversion and interpretation of MTS method. The is in the plant area. The apparent resistivity section of L1 and L2 line shows as Fig.2 and Fig.3.

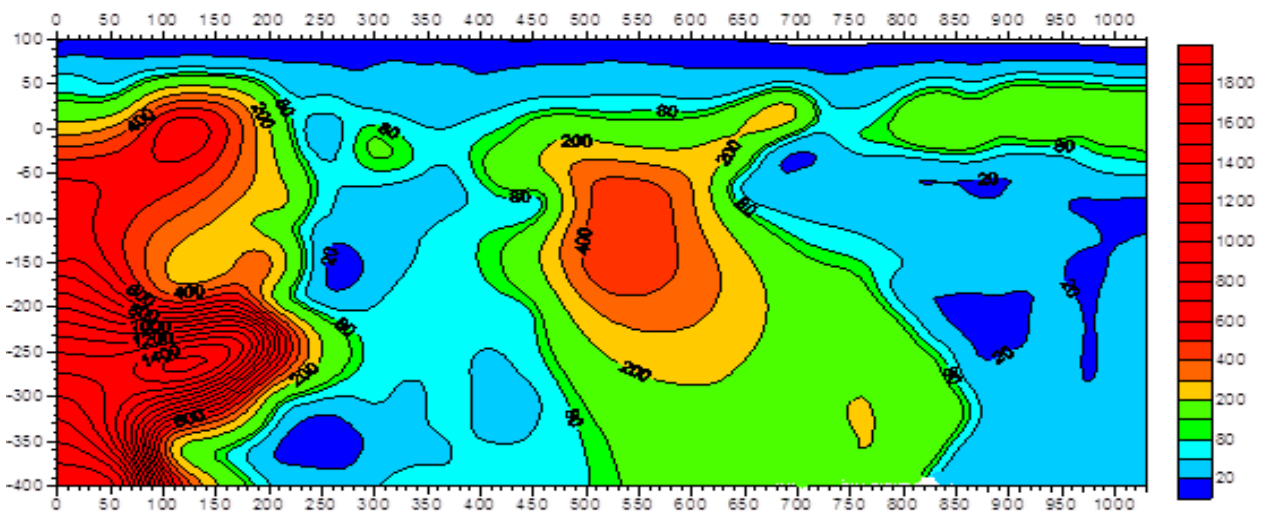

Fig.2. L1 measuring-line apparent resistivity section

The section of L1 line is divided into 4 parts, the high resistance scope are $0 \mathrm{~m}$ to $250 \mathrm{~m}$, and $450 \mathrm{~m}$ to $750 \mathrm{~m}$, the water abundance and transmissibility are poor. The low resistance scope are from 250 to $450 \mathrm{~m}$, and from 750 to the end, the depth from $55 \mathrm{~m}$ to $600 \mathrm{~m}$ is mainly the sand bed with high shale content, low resistivity, and poor water abundance.

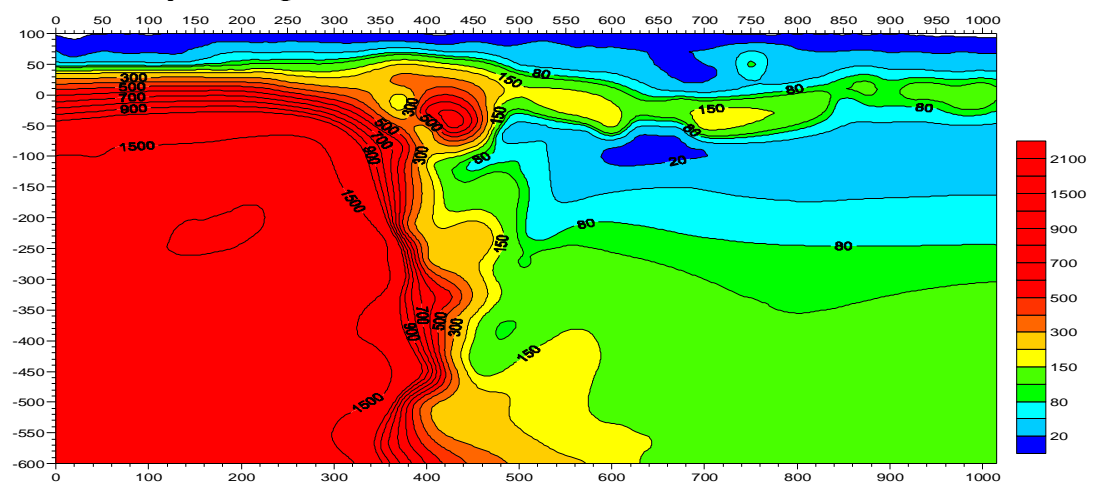

Fig.3. L2 measuring-line apparent resistivity

The L2 section is divided into two parts, the first part is high resistance area from $0 \mathrm{~m}$ to $500 \mathrm{~m}$. The depth above $55 \mathrm{~m}$ is mainly low resistance strata of silty clay mixed with silt, while under it is relatively high consolidation sand bed or glutenite of coarse particles. The second part is low resistance area from $500 \mathrm{~m}$ to end, the depth above $55 \mathrm{~m}$ is mainly low resistance strata of silty clay 
mixed with silt; and the depth from $55 \mathrm{~m}$ to $300 \mathrm{~m}$ is mainly sand bed with high shale content and low resistivity; the depth from $300 \mathrm{~m}$ to $450 \mathrm{~m}$ is high consolidation sand bed or glutenite of coarse particles. The water abundance and transmissibility are poor.

The apparent resistivity section of L3 line shows as Fig.4.

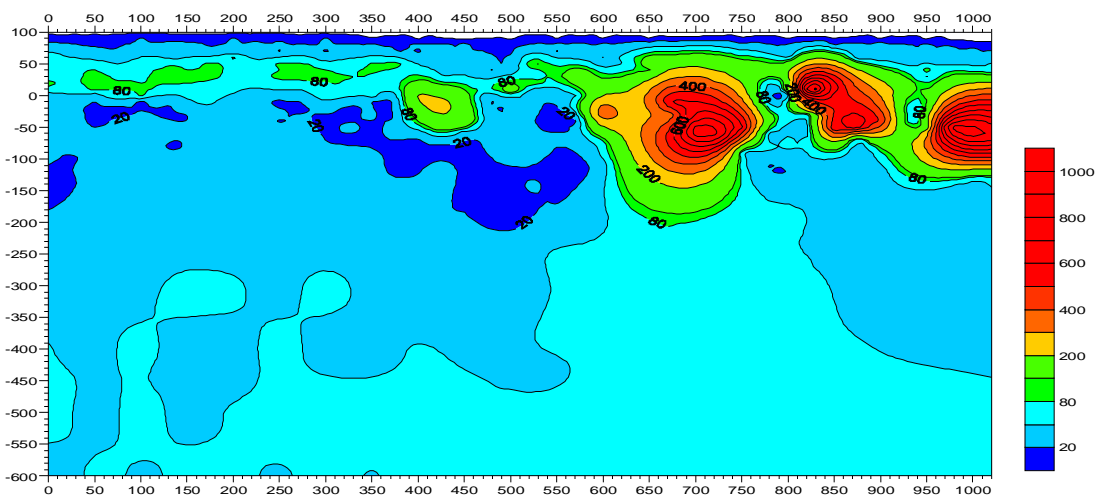

Fig.4. L3 measuring-line apparent resistivity

The entire section is a low resistance area. It is mainly low resistance strata of silty clay mixed with silt; the depth below is mainly the sand bed with high shale content. And the resistivity is low, water abundance is poor.

The apparent resistivity section of Line L4 and L5 shows as Fig.5 and Fig.6. The test result shows that the water abundance and transmissibility are also poor.

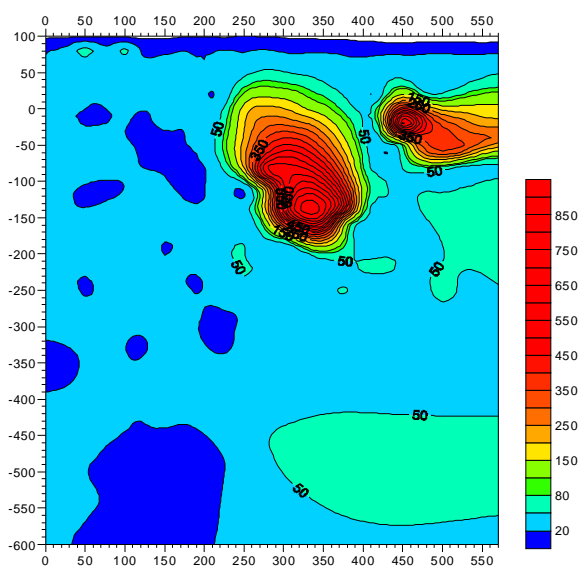

Fig.5. L4 measuring-line apparent

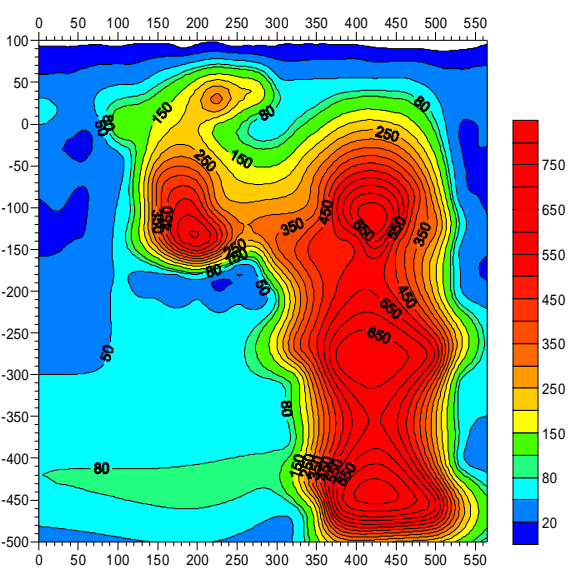

Fig.6. L5 measuring-line apparent resistivity

Electrical logging test results. The drilled data and apparent resistivity logging curve (see fig.7), at the depth of $56 \mathrm{~m}$ is mainly silty clay mixed with silt. From $56 \mathrm{~m}$ to $135 \mathrm{~m}$ is fine silt with high shale content, the maximum resistivity is merely up to $11 \Omega \cdot \mathrm{m}$; And the spontaneous potential difference is small, this reflects poor permeability and high shale content of the strata. At the depth of $135 \mathrm{~m}$ to $200 \mathrm{~m}$, the maximum resistivity is $18 \Omega \cdot \mathrm{m}$, is mainly fine silt, medium fine sand and fine sand with clay layer. The resistivity of this sand bed is at least $30-40 \Omega \cdot \mathrm{m}$, this reflects high shale content of the sand bed.

According to the two curves, the permeability sections such as $135 \mathrm{~m}-142 \mathrm{~m}, 146 \mathrm{~m}-149 \mathrm{~m}, 189 \mathrm{~m}-$ $195 \mathrm{~m}$ is relatively good, but with high shale content and small water flow. 


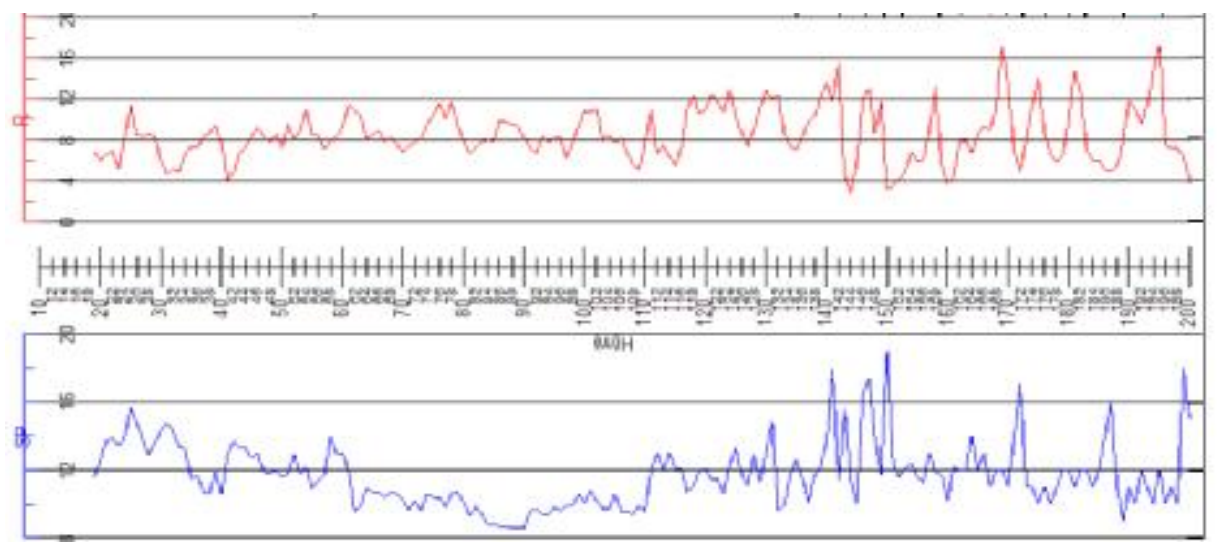

Fig.7. the test result of electrical logging

\section{Conclusion}

Through the testing data inversion and interpretation, the strata features, structure scale, groundwater type and distribution rules in the work area are well understood, the achieved data may serve as reference for groundwater exploitation and utilization in the plant area.

The test results show that water flow of single groundwater well is about $5 \mathrm{~m}^{3} / \mathrm{h}$ within $200 \mathrm{~m}$ depth range, and it is discontinuous. Up to the $600 \mathrm{~m}$ depth range, electrical property change of the formation is inconspicuous, it is concluded that water abundance of the strata is very poor, and water flow could not satisfy the $10 \mathrm{~m}^{3} / \mathrm{h}$ water demand of the industrial plant.

\section{References}

[1] Ibrahimu Chikira Mjemah, Marc Van Camp, Kristine Walraevens. Groundwater exploitation and hydraulic parameter estimation for a Quaternary aquifer in Dar-es-Salaam Tanzania. Journal of African Earth Sciences. 2009:134-146

[2] Kent, P. E., Hunt, J. A., John stone, M. A.. The geology and geophysics of coastal Tanzania. Geophysical Paper No. 6, Natural Environmental Research Council Inst. Geol. Sci. H.M.S.O. , 1971.

[3] Cagniard, L.. Basics theory of the Magnetotelluric method of geophysical prospecting. Geophysics 18. 1953 : 605-635.

[4] Fernando A. Monteiro Santos, Eugenio P. Almeida, Mota Gomes, et al. Hydrogeological investigation in Santiago Island (Cabo Verde) using magnetotellurics and VLF methods. Journal of African Earth Sciences. 2006:421-430

[5] Chave, A., Jones, A.. The Magnetotelluric Method, Theory and Practice. Cambridge University Press. 2012.

[6] Chandrasekhar E., Fontes L. Sergio , Flexor M. Jean, et al.. Magnetotelluric and aeromagnetic investigations for assessment of groundwater resources in Parnaiba basin in Piaui State of North-East Brazil. Journal of Applied Geophysics. 2009: 269-281

[7] Nazli Ismail, Gerhard Schwarz, Laust B. Pedersen. Investigation of groundwater resources using controlled-source radio magnetotellurics (CSRMT) in glacial deposits in Heby, Sweden. Journal of Applied Geophysics.2011:74-83

[8] Takumi Ueda, Yuji Mitsuhata, Toshihiro Uchida et al.. A new marine magnetotelluric measurement system in a shallow-water environment for hydrogeological study. Journal of Applied Geophysics.2014:23-31 
[9] Essam Aboud, Ramzi Saud, Theodore Asch, et al.. Water exploration using Magnetotelluric and gravity data analysis; Wadi Nisah, Riyadh, Saudi Arabia. NRIAG Journal of Astronomy and Geophysics.2014:184-191 